\title{
Research-in-action community
}

\section{Into the periphery}

\section{Juliana Schneider}

Published on: Nov 18, 2021

DOI: https://doi.org/10.21428/d2eb3cdf.a62d0d21

License: Creative Commons Attribution 4.0 International License (CC-BY 4.0). 
[This is the pre-print version of an article that has been published in Action Research, where the final version can be accessed. This pre-print version is being shared in conformity with SAGE's Green Open Access Policy.]

Imagine walking through the gallery of a major museum where some large canvases are hung, depicting grand, densely populated scenes of historical events. Where these great works are deemed masterpieces, what makes them so vital? Moving closer and closer, penetrating to the small scale within the large scale of the painting's composition, we find the artist manages to render small gestures, glances, expressions occurring amongst figures (people, and other animate beings) all of which seem to hover in the potentiality of meaning, the imminent happening of events, the 'becomingness' of the scene...Great paintings such as these give us access to the myriad relational acts playing out simultaneously, moving from what has just happened towards what is about to happen. We discover the great tableau teeming with indeterminate, unresolved, fleeting relational activity.

Anyone who wishes to inquire into their experience at work can practise and cultivate the art of paying attention to small shifts in everyday conversations or scenes as they are occurring. By doing so, practitioners can become more sensitive to ill-defined disquiets and potential openings, and respond to them in the moment. These fleeting moments matter, because they can be a doorway to moving on together in new and sometimes constructive directions. Conversely, when we fail to pay attention to the small movements in such everyday scenes, we risk missing these potential turning points altogether.

Initially, the approach described here will probably seem a little different from traditional action research, and readers may feel a bit like they are being led off into rough ground. But I hope to show that it is a path worth taking, one that is broadly in tune with the work of other scholars who advocate an aware inquiring approach to our everyday circumstances. Judi Marshall calls this 'living life as inquiry '(1999; 2016); Reason and Bradbury (2001) write of bringing ' inquiry into more and more of our moments of action - not as outside researchers but in the whole range of everyday activities.'; Torbert (2001) speaks of every action being an inquiry and every inquiry always an action, while warning of the immense demand that honing and sustaining attention in such moments requires. All these authors go on to make use of a number of core distinctions and processes, such as between first, second and third person research, and the explicit AR processes that have been developed to serve these distinctions, such as self-reflective inquiry methods, cooperative inquiry and participatory action research. However, I will not be following this direction. Instead, I want to turn around and inquire into what happens before these distinctions arise - this wellspring of experience.

I am taking the theme of this special issue as an invitation to dive deeper into this well-spring, to explore the always available experience of working in a playground teeming with indeterminate, unresolved, fleeting 
relational activity, knowing that what is happening here matters. I am curious about 'bringing inquiry into more and more of our moments of action'. By this I mean finding ways to narrate that retain the latency, the uncertain potentiality and yet the concreteness of the everyday realm. This is something that I suggest eludes the illustrative tellings of the authors I have mentioned, where the concerns, questions, meanings described are already distinct. What has helped me in this exploration is to see how some artists - novelists and performers have shared my curiosity and how they have attempted to communicate their inquiries. I have also found scholarly work, that is less often cited within the AR canon, but which has offered me language to think in the midst of this indistinctness, where perception and imagination must be as disciplined as conceptual reasoning.

So let me start with a narrative:

\section{Grasping a momentary door handle}

At the time of the following scene, I was leading a collaborative educational endeavour. The scene occurred during a difficult period in the evolution of the organisation, when there was a loss of engagement by two people in the team, whilst at the same time more responsibility was being transferred to my role due to an important colleague having just gone on maternity leave.

The scene begins at the end of one of the team's monthly meetings in which the usual agenda, related to running courses, gave way to Laura speaking of her realisation that at some point along the way - over the four years of us working together - she had disengaged herself from our work.

Laura tells us that she has come to notice that, even though she loves teaching the courses, she does not really feel part of our team. I realise that her unease is directed towards a number of people, including me. We spend the remainder of the meeting all exploring together what she had just raised.

The meeting ends.

Laura and I are each going home and I ask if she is driving, as our houses are in the same direction. She happens to not be - which is rare. She explains that a colleague gave her a lift to the meeting, and so now she is going to order a taxi. I feel my voice quickly rising to ask if she wouldn't like to walk for part of the way with me. To my surprise, she says 'yes'. There is something in her yes-saying that feels freeing, instantly. Something in my body relaxes; a tension in my stomach subsides. She smiles and moves with determination as she gathers her things inside the bag and joins me at the door. Something excites us both with anticipation. It is as though we are courting something unprecedented. We walk and talk-an easy exchange that moves with the rhythm of our steps on the pavement, our feet and our voices moving together. We are making sense of what was said in the meeting, of the importance of her having spoken. Laura acknowledges her own challenges in speaking up, of taking a stand. We visit other scenes in life where that is happening. I speak of my own recent learnings along these lines and of sometimes finding this difficult myself. Our walking and talking flows. Although immersed in the stream with her, I can 
glimpse at the same time the effect this is having on us; I can feel that this is acting into changing the unease she voiced in the meeting. But we aren't changing some-thing, we are in the midst of being changed.

Of course the way Laura spoke during the meeting had itself already provoked change, but now it was as if we were acting into the change. During the conversation with the group we had all tried to understand more what was the unease, what could be different and what had caused this, but as I can see now, this was the least effective part of 'resolving' this situation. All our attempts to 'tackle the issue' were nothing compared to the way in which her very speaking in the meeting, in the way she did, had already started to change something between us. And now she and I were walking at night through the streets of São Paulo together, which we'd never done before.

We continue walking towards my home, which is nearer than hers, until still a few blocks away Laura stops at a corner, just as we are about to start walking a new block. I stop too, not knowing why we are stopping here.

Her face looks different, slightly tense, and she tells me - whilst moving back to reach her backpack - that she has brought this book she wishes to take back to a bookshop nearby. It's a thick book she has been gifted but she knows she won't read it, and has finally got herself together to take it along in the hope of exchanging it before the deadline expires. She asks if we have gone past the bookshop and I point out that we have indeed, by quite a long way. She would have to go back about six blocks, I estimate, trying to help her in making a decision.

She pauses for a moment. I pause with her. We are both aware of a decision hovering.

I can feel in my body a mix of resistance and disappointment in having to end the walk \& talk, and I sense that she may be experiencing something similar. We seem to be aware of being poised before a coming moment rushing towards us but still as yet undetermined. She then makes a move to put the book back in her backpack and says she will go there another day. But the return to our walk and talk does not release the slight tension I feel through the pausing. Something is not quite right and I find myself saying that I will walk back with her to the bookshop and we will exchange the book. Our eyes meet for a second in acknowledgement and it's like the same excitement arises again between us as when we first began to walk.

We turn around and walk together the extra blocks and I wait with her until the exchange is all done, telling her to take her time whenever she looked back to reassure me that she was almost done. We then continue until my home, where we say goodbye as Laura decides she will continue walking to her place, buying a few groceries on the way. We hug and stumble around words, tentatively acknowledging that 
vague and yet poignant sense that had been pulsing between us as we joined one another in what felt like a tickling yes.

How to speak of these moments, in which the smallest gesture holds open a door that was not there before? It was as if between us - and the streets, and the night-sky, and the bookshop, and the book - a door appeared. This did not come out of the blue, as there had been a whole unfolding of interaction between us and within the team before this moment. And yet a new possibility had just arisen, one that could not have been made to happen. I can still feel the intensity of the moment when we stood at the street corner, holding the heavy book and faced with the question of how to go forward - together, separate, together my way, together her way? As we hugged goodbye, there was a renewed sense of who we were to each other. It was not just the book that needed exchanging, but also our worn-out history of relating.

When I said "let's walk back together to the bookshop, I will walk with you" it felt as if I was grabbing a handle and walking through a door into a new terrain. Laura had told us in the earlier meeting that she had felt she lost her voice, like she was always going along with our decisions and had stopped feeling confidence in herself in relation to the team, and also to myself as the leader of the organisation. But now, suddenly, instead of her, it was me who was adapting. I found myself changing my course. I could feel viscerally that with this move something new was happening.

During our walk together, we were continuing a change that had already begun in the team meeting when Laura voiced her unease. Indeed, the change went back even further, to when another colleague had shared with me her concern about Laura - Laura having privately confessed to her feeling outside the group. Those earlier conversations had already influenced the way I started the meeting, by inviting people to bring whatever was of importance to them, rather than sharing only the practical things that needed discussing in relation to the course. Thus, a whole set of small moves had been gathering in the period leading up to our walk. In other words, I am not suggesting that our walk in itself changed things. Rather, it was through our sensing that something was afoot, and continuing to act into that as yet unknown 'something', that the fleeting became sustained and consolidated into wider changes. From these unfolding events, Laura’s presence became more active in our meetings over the next few weeks and she began to start new initiatives, such as organising talks and events for alumni. She found new energy for a course that had been troubling her for some time, and modified it to make it her own.

I can now see this as the beginning of a transition, over the next two years, in people's sense of responsibility for the sustaining of the organisation, with some leaving and others becoming more involved. I've tracked here a particular moment which, as always, is within a whole series of movements that were happening in the organisation. Thus, I am not interested in looking at this linearly, saying that this solved that. Trying to tease out what I feel was important in the uniqueness of that unfolding scene, I am drawing on a form of thinking that Shotter (2005) has called 'withness-thinking' in contrast to 'aboutness- thinking'. But what does such thinking entail for practitioners? In describing this scene between Laura and me, my thinking was emerging 
from the small movements between our bodies - the assertive moves, the moments of hesitation, the tone of our voices, word intertwined with breath, how we held our own bodies when speaking, what was not spoken, the little silences -the fleetingness with which all of these can be perceived. I am writing in the midst of situations where I am experiencing ill-defined tensions - is it me? is it Laura? is it the night sky? Here, Shotter's notion of joint action (1995) positions attention right in the dialogical nature of inquiring with others, in that the influences that shape the gesturing and words do not all originate in the actor him-or-herself. So that in the actual moment of such events, before there is a distinct-I and a distinct-other, there is an 'in-between', open to the influences of both past and present others at the very moment of its performance'.

By focusing on the body as the main ground for this attention, I am not relying on after-the-fact-understandings such as those involved in 'reading' gestures or 'body language' as correlated to certain meanings or states. Instead I am drawing attention to a kind of thinking that moves with the fleetingness and ambiguity inherent in human action as it occurs. That we turn to exploring not what each gesture, tone, silence means, but what these evoke bodily in our tentative responding as we move together through their appearing, before they have come to mean 'this' or 'that'. This orientation to participation seems to depend on being able to perceive in ourselves and others small movements in local scenes, and being able to engage with such details as keys and clues to action. Action that is coming to matter, that is contributing to the movement of events, whose patterning over time becomes more widely recognised and spoken of.

In making such a call, I am 'in dialogue’ not only with John Shotter (e.g. 2005; 2006) but also Henri Bortoft, whose phenomenological approach draws on Goethe's (2009) scientific method in his studies of living plants (Bortoft, 1996; 2012). Bortoft's work involves reversing our current movement of thinking to see the dynamic arising of form, thus shifting attention from what has occurred (downstream) into the occurring of what occurs (upstream). The shift from the world of already identifiable things, or distinct others, to a world of happenings. To see upstream is to join the arising of the phenomenon whilst downstream is to see it after it has already appeared. Moving upstream to the wellspring from which distinctions like first, second and third person research later arise, I am suggesting we pay attention to what is happening at the periphery of our experience, at the margins of wherever the explicit processes are tending to guide our focus.

For example, in the first narrative with Laura, I recognise Judi Marshall's 'living life as inquiry’ (1999) as the same kind of inquiry as the one we were pursuing at the meeting right after Laura gave voice to her discomfort of not feeling part of the group. In that part of the scene, we had a clear, explicit issue we were looking at. As a group we were trying to question, to look at past incidents, each of us reflecting on our own part in this. This kind of inquiry is aimed at working reflectively together to find an effective strategy for change. In contrast, by inquiring after the meeting into the not yet explicit movements going on, I am trying to track how change happens more silently in the situation and how we might attend to those moments where a tiny shift occurs or an opening happens spontaneously, which if noticed and if responded to, can sustain wider changes.

Next I will offer a scene with a different understanding of a moment of action: 


\section{Staying with the unresolved}

As I gather my notes and books together at the end of a session I was leading on complexity and emergence for organisational practitioners, Anna, one of the students, walks towards me and places a chair by my side.

She begins speaking slowly, as if searching for the right words, and I can feel she is holding some agitation. She describes a scene at an airport when she was approached by someone asking her to contribute to a social project. She goes on to describe the way she spoke with this person, asking them for more details about the project, and how she eventually agreed to support it. Anna continues telling me about then boarding the plane and finding herself sitting next to a man with whom she was suddenly engaged in another conversation. She and the man discovered interesting connections between their work and exchanged telephone numbers, which then led to them meeting for lunch a few days later, exploring possibilities of collaborating in some initiatives.

All this was being narrated to me without any preface that might indicate, even slightly, what she was telling me this for. It was midway through her descriptions when I began to notice in myself a certain sense of dislocation. Normally, at this point in a conversation I would hope to know my way around it - something of her intention in wanting to speak with me would have surfaced or been declared. But here there was a different taste, as if somehow she didn't know and I didn't know. There was a taste of unfamiliarity - she was not asking my advice, she was not sharing a thought she had, she was not clear about what she was doing, and yet she seemed very clear in her sense of the importance of something rising in her which she was attempting to voice.

Towards the end of our conversation I had a glimpse, though I was still unable to articulate it to myself fully, that she was perplexed with the arising of otherness in her experience of herself, the arising of difference. Both the scenes she described, whilst they seemed ordinary enough to me, were not normal for her. They revealed a 'her' that she was perplexed by - responding to a random person who approached her, engaging in a conversation with this person to the point of agreeing to become a contributor to their project. Then speaking to a man next to her in the plane, exchanging numbers and meeting him again. This was all novel for her. Later I heard she moved to a big city, leaving her parents' house in the south of Brazil, started a $\mathrm{PhD}$, broke up with her longstanding boyfriend and was now in a new relationship.

Although I only came to see this more fully much later, I had a 'taste' of this change at the time. I was witnessing Anna's coming to see herself differently as this was happening in her speaking with me. She was not telling me about it (e.g. "I want to share how I have changed”), her noticing was happening 'live' between us. We both had the taste of something of importance, though neither of us could fully see what was actually at play, let alone articulate it between ourselves. Our joint action here meant staying in the unfolding of the scene together, without grasping for resolution. 
Artist Erin Manning (2016) emphasises the importance of the 'minor gesture', drawing on Deleuze and Guattari's (1987) concept of 'the gestural force that opens experience to its potential variation'. I experienced the 'taste of difference' that was present between Anna and me during the conversation as an example of Manning's minor gesture. And precisely because, in that moment, all that can be experienced is a feltdifferencing, this not-yet-distinct sensation tends to go by as nothing happening. How then are we to participate in such apparent nothingness?

\section{Participating whilst a some-thing is still a sense}

Juxtaposing this scene with the earlier one with Laura, I am aware that in both cases the people living through them felt a sense of 'importance' as things were unfolding. But what this 'importance' was about was not yet revealed to us. What was happening, in both scenes, was tentative and precarious. As Manning suggests, "the minor gesture often goes by unperceived, its improvisational threads of variability overlooked... And yet the minor gesture is everywhere, all the time” (p.2). It is only later, with after-the-fact thinking, that we can say what that sense of importance was about - that a sensing becomes a something. How are we to become more active participants whilst a something is still a sense?

This has become my inquiry question. I want to suggest that these discriminating senses are 'performative' in the sense that they happen bodily as we participate in the patterning of organised activity. To work from such fleeting moves demands that we remain open to 'the force of the 'as-yet-unformed' coursing through it" (Manning, 2016, p.x). Such performative capacity involves a particular kind of artistry - of being aware of minor shifts and variations, like the different tones in a piece of music that change the mood. However, to notice such minor, fleeting variations in the midst of one's own participation is demanding. It's not like listening to a piece of recorded music, where we can pause, rewind or play it one more time. When we are in the midst, we cannot stand outside the experience and give it a name. Working this way, the practice does not lend itself to conceptual objectification.

Even as I am writing this I am acutely alert to how arduous it is to argue for and allude to these phenomena. As Manning (2016) observes: whilst all the grand gestures are easy to refer to, it is the minor ones that play key parts in initiating the subtle shifts that create the conditions for grand, or any, change. "The grand is given the status it has, not because it is where the transformative power lies, but because it is easier to identify major shifts than to catalogue the nuanced rhythms of the minor. As a result, these rhythms are narrated as secondary, or even negligible” (p.1).

One recurrent situation comes to mind from my work with entrepreneurs, executives and consultants who come together in communities of practice to reflect on their everyday experiences at work. Often, they will share having taken part in meetings whilst experiencing tensions and disquiets, which they only came to see properly, or even name them as tensions, after the meeting had ended. Usually, in speaking with others about their frustrations they come closer to the nature of the unease that was so alive bodily during that meeting. Very 
rarely do they report having responded at the time to this sense rising in them, rather than coming to it in retrospect. This experience of sensing something, a vague bodily sense that does not yet belong to the spoken, is recurrently described as an almost impossible place to step into, even for the most experienced practitioners. It often feels too risky to speak in the midst of being struck, or being stirred, or not quite at ease, whilst not being sure what that struckness/stirring/disquiet is, let alone how a move will resonate with others. Yet not rising to this risk is exactly how the status quo is maintained (Shaw, 2002).

\section{How can we account for scenes of joint action?}

My inquiry has led me to another question: how may written accounts themselves - reading them, writing then, telling them - be part of developing the attentional listening and responding into evolving scenes?

In the two reflexive narrative accounts I presented earlier, I attempted to move in writing closer to the potentiality of meaning, the imminent happening of events, the 'becomingness' of the scenes as they were unfolding. Even though these narratives clearly draw on the past, on what has already happened, their aim is prospective: to evoke in both reader and writer the experience of moving towards a highly uncertain, emerging terrain of possible noticings and responses - stirring impressions, feelings, sensations, images, associations. These act as 'transitory understandings' and 'action guiding anticipations' (Shotter, 2008) that can play a role in giving us an anticipatory sense of what is to come next in the ongoing process in which we happen to be involved, feelings which are lost in descriptions from the outside.

Cunnlife and Locke (2019), in dialogue with Shotter's work (e.g. 2009), argue that abstract and generalised accounts of action do not help practitioners deal with contextualised, ambiguous and spontaneous activities. Rather, that the work of orienting our way forward lies in a guiding, anticipatory sense of 'where we may go next' from within the unfolding of a situation. This involves "navigating within an overwhelming sea of unique details - each one only becoming sensed as something to move on from, or back from, as one encounters it and somehow to create a unique course of action related to them all.” (2008, p.163). Throughout my exchanges with practitioners - whether as a teacher or as a colleague, I have met a shared frustration with a lack of thoughtful and thought-provoking accounts of practice that unfold instructively with such performative and transitory understandings of ‘striking moments' (Shotter, 2011).

To explore further the nature of such performative written accounting I turn to the work of Brazilian fiction writer Clarice Lispector. She is seen as 'the writer of the instant' (Andrade, 2017) and declared herself to be writing with the body (Lispector, 1977). The experience of reading her is of joining the coming-into-being of the writing itself. As a brief example, in the novel 'The Hour of the Star' (1977) we move with the narrator's many disquiets and reflections in coming to write, until being taken back to her own re-living of the exact moment when eyes crossed between the narrator and Macabéa, the protagonist, in a moment inside a bus in Rio de Janeiro. Lispector takes us to the tiniest fleeting and ambiguous moment that was striking enough to evoke a character, and with that one of the most acclaimed of her novels was born. I believe this move to 
earlier noticing in her own writing is what Lispector was getting at by asking "how to begin at the beginning if things happen before happening?” (Lispector, 1977, p.11, my translation).

What Lispector's readers consider her to be a master of, she describes as being very difficult to do: "what I propose myself to tell seems easy and at everyone's hand to do. But its elaboration is very difficult. Because I have to make visible that which is almost faded and which I hardly see, using hands of muddled stiff fingers to touch the invisible in the very muddle”. (Lispector, 1977, p.19, my translation). The image Lispector provides is striking in that her hands, whilst trying to get to the muddled - to the almost invisible, are themselves in the muddle. To play with what she is saying, we could imagine for instance a very different image - of her hands trying to reach for something inside an aquarium, a something we can already see and name. Instead, Lispector speaks of an immersion, of being immersed in what she is trying to see/write. In order to get to 'it', she has to touch, feel, tap her way around within the process of the 'muddle' becoming an 'it'.

Lispector's focus on being immersed in that which she is seeking to allude to speaks to me of the paradox of 'detached involvement' advocated by sociologist Norbert Elias (1998). Our culture tends to privilege the 'detachment' side of the paradox, so that we end up learning to work with what is already mostly formed. The move to the not-yet depends on a shift towards greater involvement. This means being more immersed, more receptive, more open to being affected by what is happening. And from such involvement, being able to see and notice - this capacity to see, then moving towards what Elias would describe as the detachment side of the paradox.

Trying to reach for an already identified something in an aquarium would be like the retrospective case studies that aim to provoke discussion among learners of intentionally embedded issues. In contrast, by generating narrative accounts from the 'involvement' side of Elias' paradox, or from Lispector's seeing within the muddle, we move from explanation to description. The challenge is to produce accounts that, although written after the fact, are embedded in a fast-flowing world yet to be fully determined, always open to further shifts of possibility. Accounts that honour the unfolding landscape as well as enabling novel features of that landscape to become visible, discernible, nameable, recognisable and usable for others within communities of practice. In this shift - from aboutness-writing to withness-writing - we are taking both reading and writing as practices that have the potential to generate the capacity for this demanding attention.

\section{So what am I saying?}

Throughout this article, I have been suggesting a particular way of embodying the artistry or the artful in organisational life. This becomes possible when we expand our awareness to include what is often at the periphery of our experience, still vague and ill-defined. To do this, we need to learn to be receptive and responsive, delicately activating a capacity to move 'dialogically' through ours and others' embodied-ness even if when on a telephone or on a screen. The artistry lies in listening for a way a scene is unfolding. Listening as a participant within its becoming, honing our sensitivity to the many different 'tastes' and 'tones' 
arising in our interactions with others. Listening particularly for a poignancy arising before we can know what that poignancy is. Such a moment, arising between people, as Manning (2016) suggests, 'opens up experience to new modes of expression', creating the conditions that allow for wider changes.

I propose we develop artistry in, and through, the way we recount such scenes, by staying close to the experience of participating in unfolding events through a kind of 'anticipation-guiding narrative': an account that is thinking through experiences of joint action re-lived, paying attention to the many cues in our own body in responding to the others and otherness within the shifting circumstance around us. Because all this remains at the periphery of our awareness, it is arduous to introduce this material into conversations that work with clear-cut, finished objects of perception and conceptualization. In engaging with the peripheral, I am challenging what Manning (2016) calls 'the unwavering belief' in 'the major' as the place where events make a difference. This belief only remains 'unwavering' for the lack of different accounts that widen and disrupt accepted views of what registers as change.

To play with such artistry we need to let go of the desire to know fully where we are going, how we will get there and what the outcomes will be. The difficulty is that the more attached we have become to cognitive and conceptual ways of framing effective participation, the more we have atrophied our capacity to play and be artful.

Coming back to Lispector, professor Wisnick (imoreirasalles, 2011), teaching literature at São Paulo University, describes studying Lispector's writing with his students. He found that people less experienced in literature enter more easily into what she is doing, whilst those too schooled in writing methods struggle with her writing. This resonated with my own experience when working with colleagues who are highly skilled in organisational change methodologies. It seems that the 'bareness' of a more bodily attention to experience is harder to relate to for those who have acquired highly cognitive, conceptual ways of understanding human activity, or who have become experts in the many methods available for working with organisations.

On a similar note, Rubem Braga, a Brazilian writer of chronicles and a friend of Clarice Lispector, confessed to her in a letter - after having read the recent drafts of the short stories she sent for his appreciation - that she seemed to 'catch a thousand transmission waves' that he didn't. Despite being an already established writer, he declares: "it's curious how you affect me and enrich me, and at the same time make me feel less solid and secure” (2002, p.217, my translation).

As I finish, I am aware that anyone reading this article may have felt a bit like Rubem Braga, or like Wisnick's students. In my experience, moving into the indeterminate often leads to the fear that we will be lost there. But if we develop the capacities I have been describing, we can play. We are not lost if we learn to pay attention and work together in these moments where everyone to some extent has lost their bearings. As practitioners we can invite people to become interested, without becoming anxious, in those small fleeting details which are shaping their perceptions in the weaving of something new. 


\section{References}

Andrade, W. (2017) “Clarice Lispector: Rara e Inédita”. Revista Cult 229, p. 19-23.

Bortoft, H. (1996) The Wholeness of Nature: Goethe's way of science. Edinburgh: Floris Books.

Bortoft, H. (2012) Taking Appearance Seriously: The Dynamic Way of Seeing in Goethe and European

Thought. Edinburgh: Floris Books.

Cunnlife, L. A., Locke, C. (2019) Working With Differences in Everyday Interactions through Anticipational Fluidity: A Hermeneutic Perspective. Organisation Studies 1-21. sagepub.com/journals-permissions.

Deleuze, G., Guatari, F. (1987) 1987. A Thousand Plateaus. Translated by Brian Massumi. Minneapolis: University of Minnesota Press.

Elias, N. (1998) On Civilization, Power and Knowledge, ed. S. Mennell and J.Goudsblom, Chicago, IL: University of Chicago Press.

Goethe, J. W. (2009) The Metamorphosis of Plants. Massachusetts: The MIT Press.

imoreirasalles (2011) Palestra de José Miguel Wisnik: Hora de Clarice 2011. Available at:

https://www.youtube.com/watch?v=AJvBOJXscLQ.

Lispector, C. (1977) A Hora da Estrela. Rio de Janeiro: Rocco.

Lispector, C. (2002) Correspondências. Rio de Janeiro: Rocco.

Manning, E. (2016) The Minor Gesture. Durham and London: Duke University Press.

Marshal, J. (1999). Living Life as Inquiry. Systemic Practice and Action Research. Vol 12, No 2, pp155-17.

Marshal, J. (2016). First Person Action Research: Living Life as Inquiry. London: SAGE.

Reason, P., Bradbury, H. (2001). Handbook of Action Research - Participative Inquiry and Practice. London: SAGE.

Shaw, P. (2002) Changing Conversations in Organizations: a complexity approach to change. London, Routledge.

Shotter, J. (1995). In Conversation: Joint Action, Shared Intentionality and Ethics. Theory \& Psychology, 5(1), 49-73. doi:10.1177/0959354395051003

Shotter, J. (2005) The Short Book of 'Withness' Thinking. KFC. 
Shotter, J. (2006) “Understanding Process from Within: An argument for withness-thinking” Organization Studies 27(4): 585-000 SAGE Publications. London, Thousand Oaks.

Shotter, J. (2008) Conversational Realities: Life, Language, Body and World. London: TAOS.

Shotter, J. (2009). Bateson, double description, Todes, and embodiment: Preparing activities and their relation to abduction. Journal for the Theory of Social Behavior, 39, 221-245.

Shotter, J. (2010). Adopting a Process Orientation...in Practice: Chiasmic Relations, Language, and Embodiment in a Living World. In book: Process, Sensemaking, and Organizing.

doi: $\underline{10.1093 / \text { acprof:oso/9780199594566.003.0005 }}$

Shotter, J. (2011) “Embodiment, Abduction and Expressive Movement: A new realm of inquiry?” Theory \& Psychology 1-18. Sage.

Torbet, W. (2001). The Practice of Action Inquiry. In P. Reason \& H. Bradbury (Ed.s). Handbook of Action Research Sage: London. 250-260. 